\title{
Análise Florística e Padrão Espacial da Regeneração Natural em Área de Floresta Ombrófila Mista na Região de Caçador, SC
}

\author{
Luan Demarco Fiorentin ${ }^{1}$, Saulo Jorge Téo ${ }^{1}$, Chaiane Rodrigues Schneider ${ }^{1}$, \\ Reinaldo Hoinacki da Costa ${ }^{2}$, Sanny Batista ${ }^{2}$
}

${ }^{1}$ Departamento de Ciências Florestais, Universidade do Oeste de Santa Catarina - UNOESC, Xanxerê/SC, Brasil ${ }^{2}$ Departamento Florestal, Juliana Florestal, Caçador/SC, Brasil

\begin{abstract}
RESUMO
O objetivo desta pesquisa foi analisar o efeito da pecuária extensiva sobre a composição e a diversidade florística da regeneração natural em áreas de preservação permanente de Floresta Ombrófila Mista em Caçador, SC. Os dados são provenientes de 32 parcelas de área fixa temporária $(4 \times 17 \mathrm{~m})$, distribuídas de maneira aleatória, em áreas de preservação permanente. Foi mensurado o diâmetro do colo $(10 \mathrm{~cm})$ e a altura total de todos os indivíduos que apresentaram altura superior a $30 \mathrm{~cm}$ e circunferência à altura do peito igual ou menor que $15,7 \mathrm{~cm}$ (diâmetro $\leq 5 \mathrm{~cm}$ ). Na análise florística foram encontradas 61 espécies, 52 gêneros e 30 famílias botânicas. As áreas sem a presença de gado apresentaram uma diversidade ligeiramente superior às áreas com gado. De modo geral, a composição, diversidade e a equabilidade florística entre as áreas com e sem gado foram semelhantes.
\end{abstract}

Palavras-chave: pecuária extensiva, diversidade, dispersão.

\section{Floristic Analysis and Spatial Pattern of Natural Regeneration in an Ombrophilous Mixed Forest Area, Municipality of Caçador, Santa Catarina State, Brazil}

\begin{abstract}
The objective of this research was to analyze the effect of extensive cattle raising on floristic composition and diversity of natural regeneration in permanent preservation areas of Ombrophilous Mixed Forest in the municipality of Caçador, Santa Catarina state, Brazil. Data were collected in 32 temporary fixed area plots $(4 \times 17 \mathrm{~m})$ distributed randomly in permanent preservation areas. We measured the collar diameter $(10 \mathrm{~cm})$ and total height of all individuals taller than $30 \mathrm{~cm}$, with circumference at breast height smaller than or equal to $15.7 \mathrm{~cm}$ (diameter $\leq 5 \mathrm{~cm}$ ). The floristic analysis showed 61 species, 52 genera and 30 botanical families. The areas without cattle presented diversity slightly higher than the areas with cattle. In general, the floristic composition, diversity and equability between areas with and without cattle were similar.
\end{abstract}

Keywords: extensive cattle raising, diversity, dispersion. 


\section{INTRODUÇÃO}

A regeneração natural é um fenômeno extremamente importante, altamente complexo e dinâmico, referindo-se, de modo geral, as fases iniciais do ciclo de desenvolvimento das plantas. A regeneração natural decorre da interação de processos naturais de restabelecimento do ecossistema florestal, sendo parte do ciclo de crescimento e desenvolvimento da floresta (Gama et al., 2002).

A Floresta Ombrófila Mista, também conhecida como Floresta com Araucária, representa uma importante tipologia florestal do bioma da Mata Atlântica, a qual vem sendo ocupada há décadas, em sua maioria por pequenos e médios produtores rurais. Segundo Narvaes et al. (2008), essa tipologia florestal vem sendo explorada de forma inadequada pela retirada de madeira de valor comercial de forma clandestina, ou pela substituição da floresta para o uso do solo para cultivo agrícola, exceto em pequenas áreas onde o relevo não o favorece.

Klein (1960) destaca que a vegetação predominante na região da araucária não constitui uma formação homogênea e contínua, como aparenta à primeira vista, mas é formada por múltiplas associações e agrupamentos, que se encontram nos mais variados estágios de sucessão.

A Floresta Ombrófila Mista possui uma estrutura complexa, sendo composta por espécies com elevado valor madeireiro no mercado, como Araucaria angustifolia, Ocotea porosa, Luehea divaricata e Cedrela fissilis, e outras espécies não madeiráveis, comuns nessa tipologia florestal, como Dicksonia sellowiana e Maytenus ilicifolia (Nascimento et al., 2001).

Devido à grande quantidade de pequenas propriedades rurais na região de estudo, as áreas de preservação permanente e reserva legal, foram sendo ocupadas, principalmente, para o desenvolvimento de atividades relacionadas à pecuária, em virtude das poucas e pequenas áreas para o manejo do gado.

O distúrbio causado na floresta pelo pastoreio do gado afeta principalmente a composição das espécies e a estrutura das comunidades, através da alteração do recrutamento entre espécies pastoreadas e não pastoreadas (Leege et al., 1981). Araújo (2010) avaliou o pastoreio bovino em uma área com gado em comparação a outra área sem gado há dois anos sobre a estrutura da mata ciliar no Arroio Espinilho, em Sant'Ana do Livramento, RS, onde, segundo a autora, existe um efeito negativo no desenvolvimento dos indivíduos da regeneração natural nessas áreas, o que, possivelmente, pode ser atribuído ao pisoteio e/ou herbivoria do gado.

Já Sampaio \& Guarino (2007) avaliaram os efeitos do pastoreio de bovinos na estrutura de diversas espécies, em fragmentos de Floresta Ombrófila Mista, nos estados de Santa Catarina e Rio Grande do Sul. Para a espécie Araucaria angustifolia, os efeitos do pastoreio variaram em função das características ambientais e da intensidade e frequência de pastoreio, mas não ocorrendo um padrão em resposta ao manejo do gado.

Em virtude das poucas informações a respeito dos efeitos do manejo do gado sobre as áreas de florestas nativas, o presente estudo teve como objetivo analisar a composição e a diversidade florística da regeneração natural florestal sujeita à pecuária extensiva em áreas de preservação permanente de Floresta Ombrófila Mista na região de Caçador, SC.

\section{MATERIAL E MÉTODOS}

\section{1. Área de estudo}

A presente pesquisa foi realizada em áreas de preservação permanente (APPs) com e sem pecuária extensiva, pertencentes à empresa Juliana Florestal Ltda., associada à Frame Madeiras Especiais Ltda., na região de Caçador, Santa Catarina. As APPs da empresa são compostas por espécies nativas características da região de estudo, as dimensões dessas variam conforme cada fragmento florestal, em conformidade com o Código Florestal Brasileiro.

De acordo com Prates et al. (1989), o município de Caçador apresenta o clima Cfb (clima subtropical, com verões brandos), conforme a classificação climática de Köppen. A temperatura média anual do município varia de $14{ }^{\circ} \mathrm{C}$ a $16^{\circ} \mathrm{C}$. A precipitação pluviométrica total anual é de 1.300 a $2.000 \mathrm{~mm}$ e a umidade relativa do ar média é de $78,1 \%$ a 82,9\%. Quanto à vegetação, originalmente ocorriam a Floresta Ombrófila Mista e Campos do Planalto. As classes predominantes de solos na região do presente estudo são Latossolos e Cambissolos. 


\subsection{Coleta de dados}

Os dados foram obtidos por meio de medições de parcelas de área fixa temporárias, distribuídas de maneira aleatória em toda a área de estudo, com auxílio de mapas de escala 1:7.500. Foram medidas 21 unidades amostrais em áreas com gado e 11 unidades amostrais em áreas sem gado, perfazendo um total de 32 parcelas. A diferença no número de unidades amostrais medidas entre as áreas se deve ao fato de que nos locais onde existia a presença de gado, o número de indivíduos contidos na parcela era muito alto quando comparado com as parcelas onde não existia a presença de gado, portanto optou-se por medir maior número de unidades amostrais em locais onde não existia pecuária extensiva. As áreas sujeitas à presença bovina apresentaram um grau de ocupação médio de 22 indivíduos/ha.

As unidades amostrais de área fixa apresentaram forma retangular, com dimensões de $4 \times 17 \mathrm{~m}\left(68 \mathrm{~m}^{2}\right)$, conforme recomendado por Gama et al. (2001). A unidade amostral de formato retangular é recomendável para florestas nativas em que existe alta variabilidade e devido às facilidades de instalação e medição no campo. A instalação da unidade amostral foi realizada através de uma trilha central, demarcada por duas estacas de metal delimitando o comprimento da parcela. Para o controle da largura da unidade amostral foi utilizada uma trena; nela, todos os indivíduos classificados como regeneração florestal presentes até 2 metros da trilha central foram medidos.

Dentro das unidades amostrais foram medidos todos os indivíduos considerados de regeneração natural florestal, ou seja, todos os indivíduos arbóreos que apresentaram altura () a partir de $30 \mathrm{~cm}$, até a circunferência à altura do peito () igual ou menor de $15,7 \mathrm{~cm}$, com a finalidade de avaliar a composição e a diversidade florística, bem como as características fitossociológicas do local. Para cada indivíduo amostrado foram anotadas as seguintes informações: nome popular da espécie, diâmetro de colo a $10 \mathrm{~cm}$ de altura (), medido com paquímetro digital, e altura total (), medida com fita métrica ou hipsômetro Haglöf.

O nome científico de cada espécie florestal foi obtido na literatura e pela consulta a especialistas no Herbário do Departamento de Ciências Florestais da Universidade Federal do Paraná, localizado em Curitiba.

\subsection{Análises dos dados}

Inicialmente foi analisada a suficiência amostral através da curva espécie-parcela, bem como a composição florística nas áreas com e sem a presença de gado. Através do índice de Payandeh, calculou-se o grau de dispersão das espécies florestais encontradas em ambas as áreas. A diversidade florística foi calculada através do índice de diversidade de Shannon e Wiener, enquanto a uniformidade foi calculada pelo índice de equabilidade de Pielou.

O índice de Payandeh, representado pela Equação 1 , avalia o grau de dispersão das espécies florestais. Esse método determina o grau de agregação através da relação entre a variância e a média do número de árvores por parcela. $\mathrm{O}$ valor desse índice menor que 1,0 indica a inexistência de agrupamento das espécies, ou seja, dispersão aleatória (AL), valor entre 1,0 e 1,5 indica tendência a agrupamento (TA) e valor maior que 1,5 indica agrupamento (AG) (Carvalho, 1982; Nascimento et al., 2001).

$P=\frac{v}{m}$

em que: = índice de Payandeh; = variância do número de plantas, por unidade amostral; = média do número de plantas por unidade amostral.

O grau de dispersão pode ser classificado em aleatório, uniforme e agregado, dependendo do valor encontrado pelo índice. De acordo com Odum (1988), a distribuição aleatória ocorre onde o ambiente é muito homogêneo e onde não há tendência à agregação, já a distribuição uniforme ocorre onde a competição é alta entre os indivíduos ou há um antagonismo positivo que provoque um espaçamento uniforme, a distribuição agregada é a forma mais comum, representado por agrupamentos de diversos graus.

O índice de diversidade de Shannon e Wiener (Equação 2) mostra a diversidade de espécies, contudo é afetado por espécies raras (Kanieski, 2010).

$H^{\prime}=-\sum_{i=1}^{k}\left(p_{i}\right) *\left(\ln p_{i}\right)$

em que: = índice de diversidade de Shannon e Wiener (nats/indivíduo); = número total de espécies; = abundância proporcional da espécie(;); = número de indivíduos da espécie; = número total de indivíduos.

$\mathrm{O}$ índice de uniformidade mostra de que forma o número de indivíduos está distribuído entre as espécies, proporcionando maior ou menor uniformidade. $\mathrm{O}$ 
índice de equabilidade de Pielou mede a proporção da diversidade observada em relação à máxima diversidade esperada (Kanieski, 2010), conforme representado pela Equação 3.

$J^{\prime}=\frac{H^{\prime}}{H^{\prime}{ }_{\max }}$

em que: = índice de equabilidade de Pielou; = Shannon e Wiener para a comunidade florestal; = ; = número de espécies na comunidade.

\section{RESULTADOS E DISCUSSÃO}

\subsection{Suficiência amostral}

A suficiência amostral realizada na área com a presença de gado e na área sem a presença de gado foi avaliada através do número acumulado de espécies, representado na Figura 1. O número de espécies amostradas aumentava conforme novas unidades amostrais eram medidas, até um ponto de estabilização da curva acumulativa, caracterizada pela ausência de novas espécies.

Pode-se notar que existe uma tendência à estabilização do número de espécies acumuladas em ambas as áreas devido à ausência de ingresso de novas espécies no processo de amostragem. Na área sem gado, a estabilização é obtida, inicialmente, na parcela 14 , porém ainda ocorre um pequeno aumento devido ao acréscimo de novas espécies e, posteriormente, tem-se uma nova tendência de estabilização. Já na área sujeita à presença de gado a estabilização ocorre depois da parcela 10, devido a não inclusão de novas espécies.

No entanto, esses resultados indicam que, a princípio, as 21 parcelas amostradas na área sem gado e as 11 parcelas amostradas na área com gado foram suficientes para caracterizar a vegetação em estudo, em termos de composição florística, devido ao número elevado de espécies amostradas e à tendência de estabilização da curva espécie-parcela.

\subsection{Composição florística}

Foram amostrados, no total, 3.013 indivíduos considerados de regeneração natural florestal. $\mathrm{Na}$ análise florística foram encontradas 61 espécies identificadas, sendo seis delas somente até gênero, e 10 espécies não identificadas, 52 gêneros e 30 famílias botânicas. A Tabela 1 apresenta a relação das famílias botânicas e das espécies amostradas na área com gado $(\mathrm{AcG}) \mathrm{e}$ na área sem gado (AsG), juntamente com o padrão de distribuição das espécies.

$\mathrm{Na}$ área com ocorrência de gado foram amostrados 1.677 indivíduos pertencentes à regeneração florestal, distribuídos em 51 espécies identificadas e três não identificadas, 45 gêneros e 29 famílias botânicas. Enquanto que na área onde não havia gado foram amostradas 1.336 indivíduos, distribuídos em 50 espécies identificadas e oito não identificadas, 44 gêneros e 27 famílias botânicas. Observa-se que na área com gado foram amostrados 341 indivíduos
CURVA ESPÉCIA-PARCELA ÁREA SEM GADO

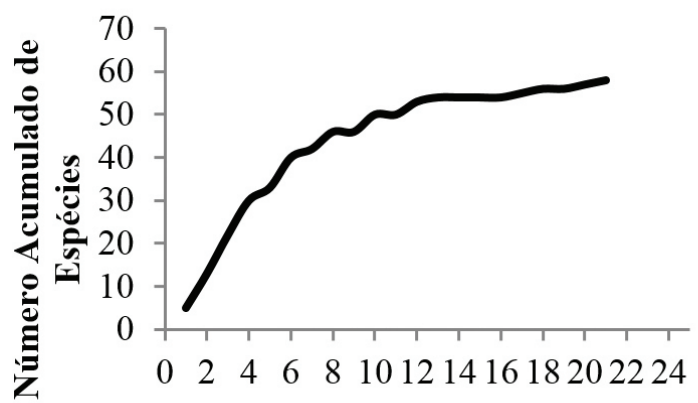

Número de Parcelas
CURVA ESPÉCIE-PARCELA ÁREA COM GADO

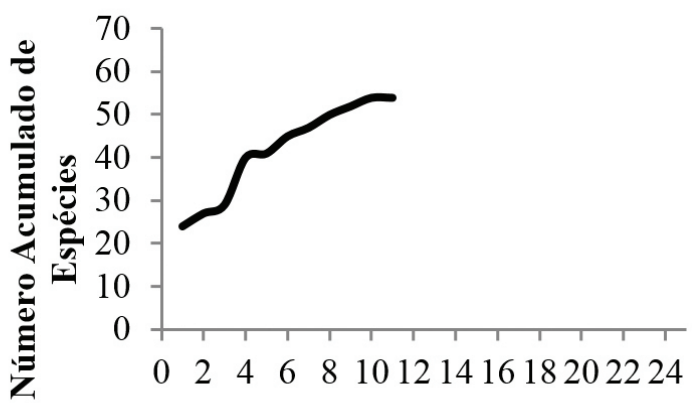

Número de Parcelas

Figura 1. Número acumulado de espécies em área sem gado e área com gado para regeneração natural em Floresta Ombrófila Mista na região de Caçador, SC.

Figure 1. Cumulated number of species in area without cattle and area with cattle for natural regeneration, in Ombrophyllous Mixed Forest, at Caçador region, SC. 
Tabela 1. Famílias botânicas e espécies amostradas com respectivos padrões de dispersão agregado (AG), tendência a agregação $(\mathrm{TA})$ e aleatório $(\mathrm{AL})$ em áreas com gado $(\mathrm{AcG})$ e em áreas sem gado $(\mathrm{AsG})$ para regeneração natural em Floresta Ombrófila Mista na região de Caçador, SC.

Table 1. Botanical families and species sampled with respective dispersion patterns aggregate (AG), aggregation tendency (TA) and random (AL) at the area with cattle $(\mathrm{AcG})$ and area without cattle $(\mathrm{AsG})$ for natural regeneration, in Ombrophyllous Mixed Forest, at Caçador region, SC.

\begin{tabular}{|c|c|c|c|}
\hline Famílias & Espécies & AcG & AsG \\
\hline \multirow{2}{*}{ Anacardiaceae } & Lithraea brasiliensis Marchand & AG & TA \\
\hline & Schinus terebinthifolius Raddi & AG & AG \\
\hline \multirow{2}{*}{ Annonaceae } & Annona crassiflora Mart & AG & $\mathrm{AG}$ \\
\hline & Rollinia emarginata Schltdl. & AG & - \\
\hline \multirow{4}{*}{ Aquifoliaceae } & Ilex brevicuspis Reissek & $\mathrm{TA}$ & TA \\
\hline & Ilex dumosa Reissek & TA & - \\
\hline & Ilex microdonta Reissek & $\mathrm{AG}$ & $\mathrm{AG}$ \\
\hline & Ilex paraguariensis A. St.-Hil. & $\mathrm{AG}$ & AG \\
\hline Araucariaceae & Araucaria angustifolia (Bertol.) Kuntze & $\mathrm{AG}$ & $\mathrm{AG}$ \\
\hline Asteraceae & Piptocarpha angustifolia Dusén ex Malme & $\mathrm{TA}$ & $\mathrm{TA}$ \\
\hline Bignoniaceae & Jacaranda micrantha Cham. & AG & AG \\
\hline Canellaceae & Cinnamodendron dinisii Schwacke & AG & AG \\
\hline Cannabaceae & Celtis iguanaea (Jacq.) Sargent & AG & AG \\
\hline \multirow{2}{*}{ Celastraceae } & Maytenus muelleri Schwacke & AG & TA \\
\hline & Maytenus sp. & - & $\mathrm{TA}$ \\
\hline \multirow{2}{*}{ Cunoniaceae } & Lamanonia ternate Vell. & AG & TA \\
\hline & Weinmannia humilis Engl. & - & $\mathrm{AG}$ \\
\hline \multirow{3}{*}{ Euphorbiaceae } & Sapium glandulatum (Vell.) Pax & $\mathrm{AG}$ & $\mathrm{AG}$ \\
\hline & Sebastiania brasiliensis Spreng. & AG & - \\
\hline & Sebastiania commersoniana L. B. Sm. e Downs & $\mathrm{AG}$ & $\mathrm{AG}$ \\
\hline \multirow{2}{*}{ Fabaceae } & Dalbergia frutescens (Vell.) Britton & AG & AG \\
\hline & Inga vera Willd. & AG & $\mathrm{AG}$ \\
\hline \multirow{4}{*}{ Lauraceae } & Cinnamomum visiculosum (Nees) Kosterm. & - & AG \\
\hline & Nectandra megapotamica (Spreng.) Mez & $\mathrm{AL}$ & $\mathrm{AL}$ \\
\hline & Ocotea elegans $\mathrm{Mez}$ & AG & AG \\
\hline & Ocotea porosa (Nees e Mart.) Barroso & $\mathrm{TA}$ & AG \\
\hline Loganiaceae & Strychnos brasiliensis (Spreng.) Mart. & AG & AG \\
\hline Meliaceae & Cedrella fissilis Vell. & AG & - \\
\hline \multirow{10}{*}{ Myrtaceae } & Acca sellowiana (O. Berg) Burret & - & TA \\
\hline & Campomanesia xanthocarpa Mart. ex O. Berg & $\mathrm{AL}$ & $\mathrm{AG}$ \\
\hline & Eugenia pyriformis Cambess. & TA & AG \\
\hline & Myrcea sp. & - & $\mathrm{TA}$ \\
\hline & Myrceugenia miersiana (Gardner) D. Legrand e Kausel & AG & $\mathrm{AG}$ \\
\hline & Myrcia sp (Aubl.) DC. & AG & AG \\
\hline & Myrcia obtecta (O. Berg) Kiaersk. & $\mathrm{AL}$ & TA \\
\hline & NI2 & - & $\mathrm{AL}$ \\
\hline & NI3 & - & AG \\
\hline & Psidium cattleianum Sabine & AG & AG \\
\hline \multirow{2}{*}{ Phytolaccaceae } & Myrciaria tenella (DC.) O. Berg & AG & $\mathrm{AL}$ \\
\hline & Seguieria langsdorffii Moq. & AG & - \\
\hline Picramniaceae & Picramnia parvifolia Engl. & AG & - \\
\hline Podocarpaceae & Podocarpus lambertii Klotzsch ex Endl. & AG & - \\
\hline Primulaceae & Myrsine umbellata Mart. & AG & $\mathrm{AG}$ \\
\hline \multirow{2}{*}{ Rhamnaceae } & NI8 & AG & - \\
\hline & Rhamnus sphaerosperma Sw. & AG & AG \\
\hline Rosaceae & Prunus myrtifolia (L.) Urb. & TA & $\mathrm{AG}$ \\
\hline
\end{tabular}


Tabela 1. Continuação...

Table 1. Continued...

\begin{tabular}{|c|c|c|c|}
\hline Famílias & Espécies & AcG & AsG \\
\hline Rubiaceae & Psychotria sp. & - & TA \\
\hline \multirow{2}{*}{ Rutaceae } & Metrodorea nigra A. St.-Hil & $\mathrm{AG}$ & $\mathrm{AL}$ \\
\hline & Zanthoxylum rhoifolium Lam. & AG & AG \\
\hline \multirow{4}{*}{ Salicaceae } & Banara tomentosa Clos & TA & - \\
\hline & Casearia decandra Jacq. & AG & TA \\
\hline & NI4 & - & TA \\
\hline & Xylosma sp. & - & TA \\
\hline \multirow{4}{*}{ Sapindaceae } & Allophylus edulis (A. St.-Hill., A. Juss. e Cambess.) Hieron. Ex Niederl. & AG & AG \\
\hline & Cupania vernalis Cambess. & AG & AG \\
\hline & Diatenopteryx sorbifolia Radlk. & AG & AG \\
\hline & Matayba elaeagnoides Radlk. & AG & AG \\
\hline \multirow{3}{*}{ Solanaceae } & Solanum mauritianum Scop. & TA & - \\
\hline & Vassobia breviflora (Sendtn.) Hunz. & AG & - \\
\hline & Cestrum sp. & - & AG \\
\hline \multirow{2}{*}{ Styracaceae } & Styrax leprosus Hook. e Arn. & AG & AG \\
\hline & Styrax sp. & - & AG \\
\hline \multirow{2}{*}{ Symplocaceae } & Symplocos tenuifolia Brand & AG & - \\
\hline & Symplocos uniflora (Pohl) Benth. & - & TA \\
\hline Winteraceae & Drimys brasiliensis Miers & AG & AG \\
\hline \multirow{6}{*}{ Não Identificada } & NI1 & TA & AG \\
\hline & NI5 & - & TA \\
\hline & NI6 & - & AG \\
\hline & NI7 & TA & - \\
\hline & NI9 & - & TA \\
\hline & NI10 & - & TA \\
\hline
\end{tabular}

a mais em relação à área sem gado, apesar de na área sem gado a intensidade amostral ter sido maior, com 21 parcelas, enquanto que na área com gado foram medidas 11 parcelas. Caldato et al. (1996) avaliaram a regeneração natural na Reserva Genética Florestal de Caçador, SC, próximo à área do presente estudo, na qual encontraram 44 espécies, distribuídas em 37 gêneros e 26 famílias botânicas.

Barddal et al. (2004) avaliaram a estrutura de um sub-bosque de uma Floresta Ombrófila Mista Aluvial no munícipio de Araucária, PR, amostrando 907 indivíduos, distribuídos em 39 espécies, 36 gêneros e 23 famílias botânicas. Já Narvaes et al. (2005) avaliaram a regeneração natural na Florestal Nacional de São Francisco de Paula, RS, encontrando grande variabilidade na composição florística, amostrando 109 espécies, distribuídas em 88 gêneros e 46 famílias botânicas.

As famílias botânicas mais representativas em termos de número de indivíduos amostrados para a área com gado foram a Myrtaceae (415 indivíduos), Sapindaceae (316 indivíduos) e Euphorbiaceae (134 indivíduos), equivalendo a 51,89\% do número total de indivíduos amostrados na área. Para a área sem gado, as famílias que se destacaram no número de espécies foram a Myrtaceae (276 indivíduos), Sapindaceae (225 indivíduos) e Primulaceae (150 indivíduos), as quais equivaleram a 43,76\% do total de indivíduos. A Figura 2 representa as famílias botânicas encontradas nas diferentes áreas com respectivo número de indivíduos amostrados.

As famílias Symplocaceae e Rubiaceae, para a área com gado, e a família Asteraceae, para a área sem gado, foram as menos representativas, com apenas um indivíduo amostrado cada.

A Figura 3 representa as famílias botânicas mais representativas em termos de número de espécies. Para a área sem gado, as famílias de destaque foram a Myrtaceae (10 espécies), Sapindaceae e Lauraceae (quatro espécies), as quais representam 33,96\% do 

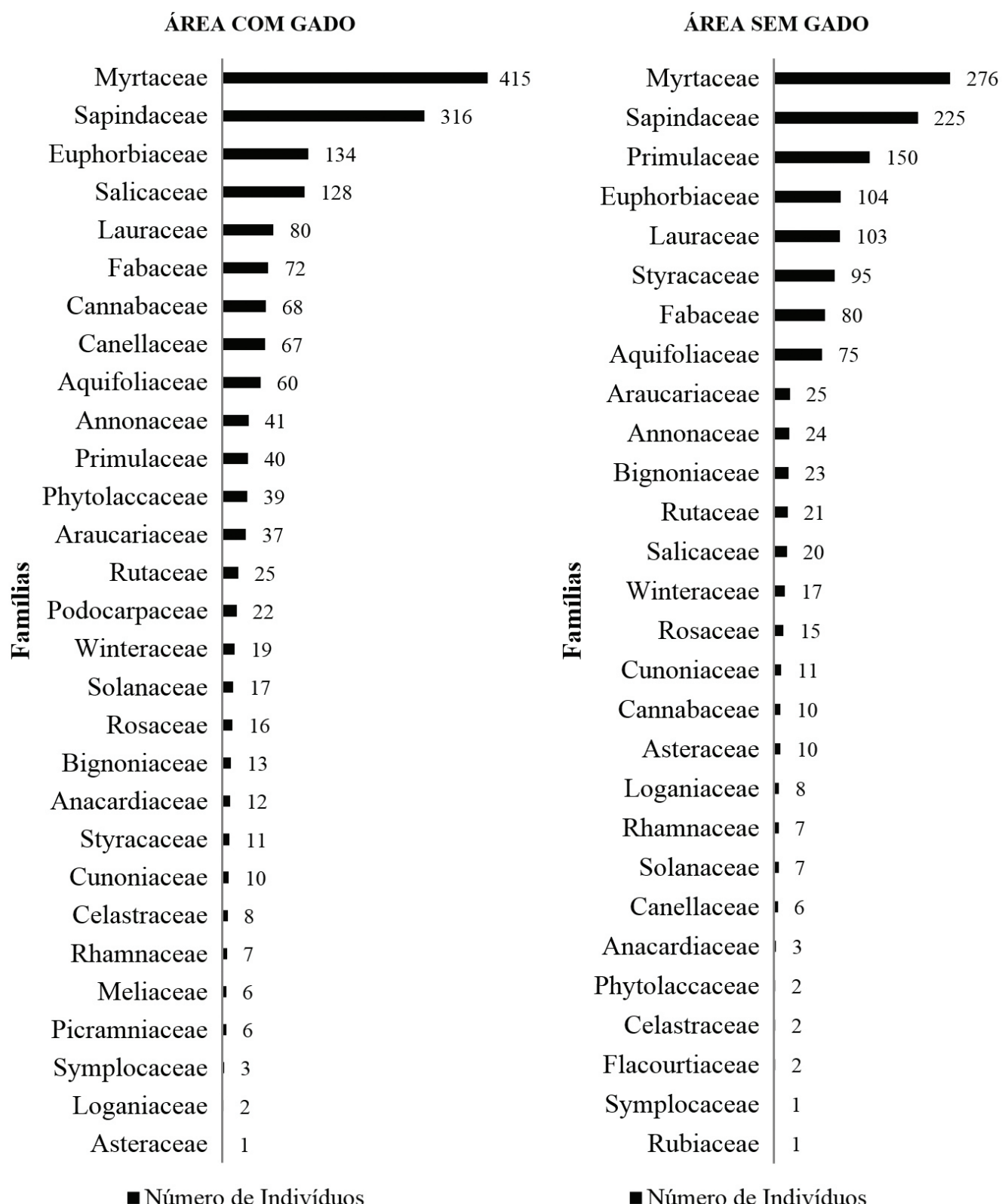

Figura 2. Famílias botânicas e número de indivíduos na área com gado e na área sem gado para regeneração natural em Floresta Ombrófila Mista na região de Caçador, SC.

Figure 2. Botanical families and number of individuals in area with cattle and area without cattle for natural regeneration, in Ombrophyllous Mixed Forest, at Caçador region, SC.

total de espécies. Para a área com gado, o resultado foi semelhante, as famílias mais representativas foram a Myrtaceae (seis espécies) Sapindaceae e Aquifoliaceae (quatro espécies), as quais equivalem a $26,42 \%$ do total de espécies. Em ambas as áreas, as famílias mais representativas foram semelhantes. No entanto, nota-se que as famílias Flacourtiaceae e Annonaceae ocorrem apenas na área sem gado, enquanto a família Podocarpaceae ocorre apenas na área com gado.

Para Caldato et al. (1996), na Reserva Genética de Caçador, SC, as famílias mais representativas foram a Myrtaceae, Lauraceae e Sapindaceae, quando se considerou o número de espécies, sendo essas semelhantes com relação a área sem gado. Narvaes et al. (2005) 


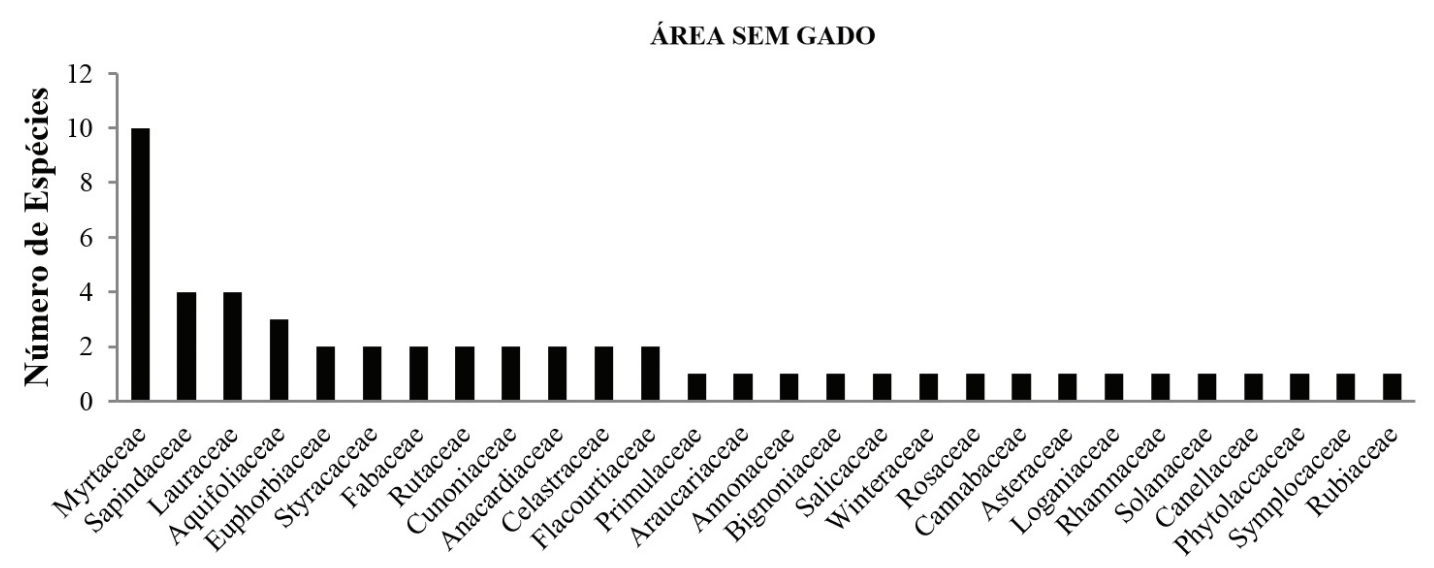

Famílias

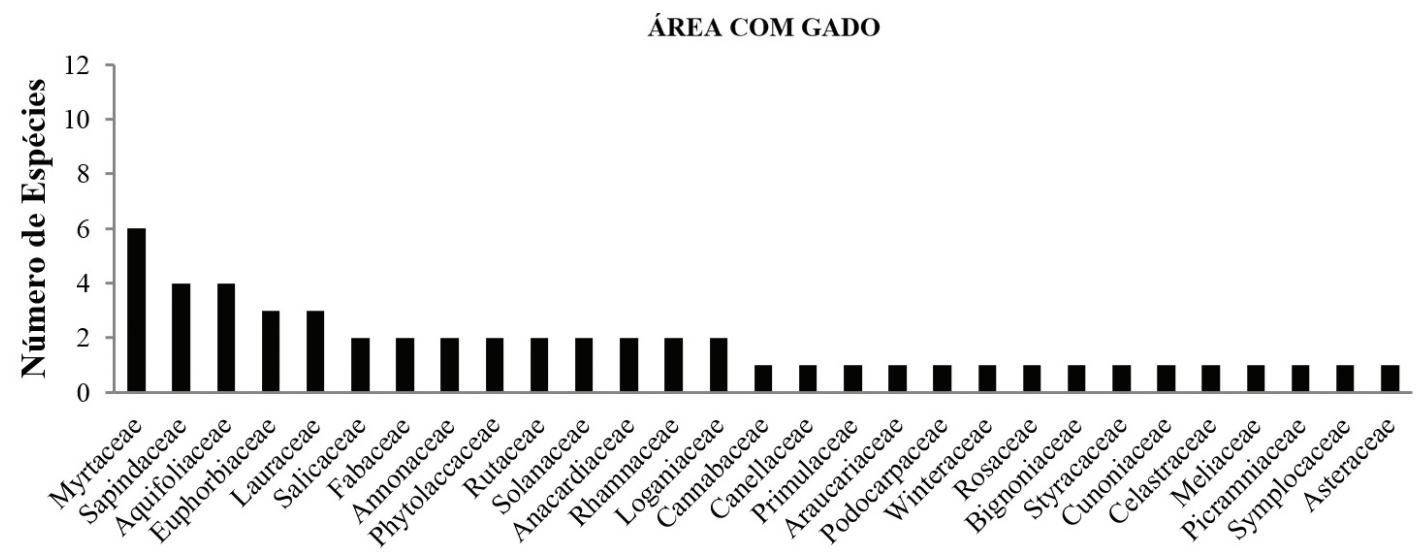

Famílias

Figura 3. Número de espécies por família botânica nas áreas sem gado e nas áreas com gado para regeneração natural em Floresta Ombrófila Mista na região de Caçador, SC.

Figure 3. Number of species according to botanical family in area without cattle and area with cattle for natural regeneration, in Ombrophyllous Mixed Forest, at Caçador region, SC.

encontraram como as famílias mais representativas na Floresta Nacional de São Francisco de Paula, RS, Myrtaceae (21 espécies), Solanaceae (11 espécies) e Lauraceae (10 espécies).

É importante ressaltar que quando se trata de Floresta Ombrófila Mista, geralmente a família de maior destaque é a Myrtaceae. Essa família ocorre em grande destaque também na população arbórea adulta pois, segundo Seger et al. (2005), a maior quantidade de espécies dessa família forma, praticamente, um padrão florístico para essa tipologia florestal. Em estudo realizado anteriormente na mesma área da presente pesquisa, porém avaliando a estrutura e a composição da fração arbórea (diâmetro à altura do peito $\geq 5 \mathrm{~cm}$ ), Téo et al. (2012) encontraram como famílias de destaque Myrtaceae (sete espécies), Aquifoliaceae e Asteraceae (quatro espécies), Lauraceae e Fabaceae (três espécies).

Seger et al. (2005) ainda destacam que a não observação das famílias Myrtaceae, Fabaceae, Sapindaceae e, principalmente, Lauraceae em florestas nativas é considerada um fato atípico e está ligada diretamente à uma intensa exploração seletiva ocorrida no passado, o que faz com que atualmente sejam raras na área. Contudo, esse fato não é verificado nas áreas da presente pesquisa, indicando que essas famílias apresentam boa representatividade na região. 


\subsection{Dispersão}

As estimativas do padrão de distribuição das espécies podem ser observadas na Tabela 1 e na Figura 4. Verifica-se que a maior parte das espécies apresentou índice de Payandeh superior a 1,0, indicando predomínio de espécies com padrão agregado e com tendência à agregação. Esse fato também foi verificado por Nascimento et al. (2001) em área de Floresta Ombrófila Mista em Nova Prata, RS, na qual as principais espécies da comunidade florestal apresentaram distribuição agregada ou tendendo à agregação.

Nota-se que na área com gado as espécies com padrão de distribuição agregado equivaleram a $76 \%$, enquanto que na área sem gado essa proporção foi menor (64\%). Houve grande diferença entre os dois estratos estudados quanto ao padrão de distribuição com tendência ao agrupamento, enquanto que para o padrão aleatório a diferença foi pequena.

As principais espécies que apresentaram padrão de dispersão agregado tanto na área com gado quanto na área sem gado foram Annona crassiflora, Ilex paraguariensis, Araucaria angustifolia, Jacaranda micranta, Sebastiania
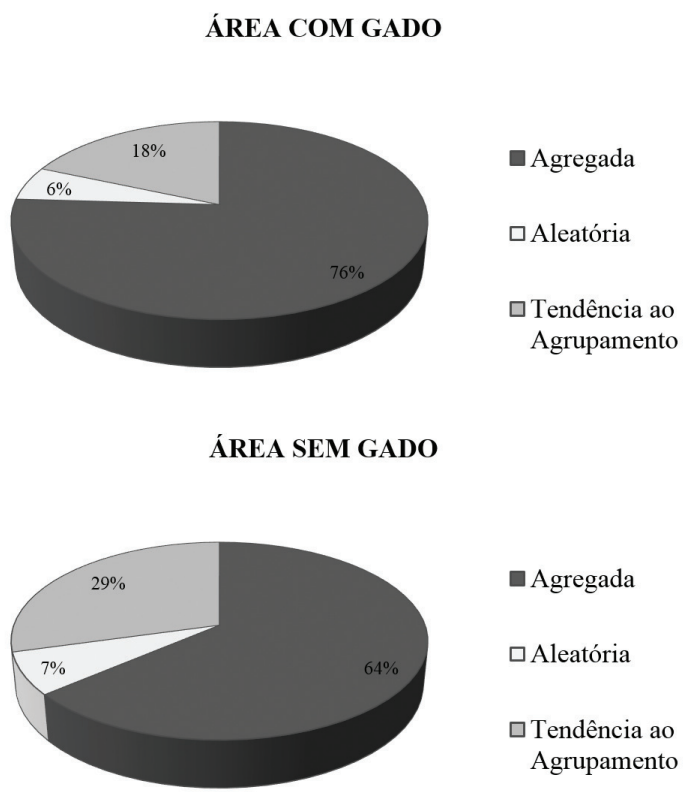

Figura 4. Padrão de distribuição das espécies em áreas com gado e áreas sem gado para regeneração natural em Floresta Ombrófila Mista na região de Caçador, SC.

Figure 4. Patterns distribution of species in area with cattle and area without cattle for natural regeneration, in Ombrophyllous Mixed Forest, at Caçador region, SC. commersoniana, Inga vera, Ocotea elegans, Myrcia sp, Myrsine umbellata, Styrax leprosus, Allophylus edulis, Cupania vernalis e Matayba elaeagnoides. Enquanto que apenas as espécies Ilex brevicuspis e Piptocarpha angustifolia apresentaram dispersão com tendência a agregação e Nectandra megapotamica se distribuiu aleatoriamente em ambas as áreas analisadas.

Segundo Nascimento et al. (2001), em florestas secundárias pode ser encontrada uma elevada densidade de árvores por hectare, representada por arvoretas de pequeno porte que habitam os primeiros estratos da vegetação e indivíduos jovens de árvores de grande porte do dossel da floresta, isso faz com que exista uma participação acentuada desses indivíduos de menor porte formando pequenas e densas manchas na vegetação e proporcionando uma distribuição espacial agregada ou tendendo à agregação.

\subsection{Diversidade florística e equabilidade}

A diversidade florística, avaliada pelo índice de diversidade de Shannon e Wiener, indicou que as áreas onde há gado, com valor de 2,99 nats/indivíduo (nats/ind.), possuem diversidade inferior em relação às áreas sem gado, nas quais o valor encontrado foi de 3,13 nats/ind.

Araújo (2010), comparando a diversidade florística da regeneração natural entre áreas com e sem gado em Floresta Ombrófila Mista na mata ciliar do Arroio Espinilho, em Sant'Ana do Livramento, RS, também encontrou maior diversidade para a área sem gado, com valor de 2,34 nats/ind., enquanto que na área com gado o valor de diversidade foi de 2,30 nats/ind. Ambas as áreas avaliadas pela autora apresentaram valores de diversidade inferiores ao presente estudo, indicando que a área analisada neste estudo possui maior diversidade florística.

A diversidade encontrada para as áreas do presente estudo foram também superiores em relação à encontrada por Narvaes et al. (2005) na Floresta Nacional de São Francisco de Paula, RS, onde o índice de diversidade foi de 2,22 nats/ind., e à encontrada por Mauhs (2002), que avaliou a regeneração natural em fragmento de Floresta Ombrófila Mista exposto a diversos tipos de perturbações antrópicas, com valor de 2,43 nats/ind. para o componente plântulas.

Através de uma comparação entre diversos índices de diversidade de Shannon e Wiener obtido por 
diferentes autores verifica-se que na Floresta Ombrófila Mista a maioria dos valores estão concentrados entre 2,30 a 8,11 nats/ind. (Durigan, 1999; Nascimento et al., 2001; Lingner et al., 2007; Negrelle \& Silva, 1992; Narvaes et al., 2005; Mauhs, 2002; Araújo, 2010). Segundo Nascimento et al. (2001), valores de diversidade próximos de 3,0 nats/ind. caracterizam uma diversidade mediana, como é esperado em florestas que sofreram influências antrópicas, com estágio de sucessão secundária e no domínio da Floresta Ombrófila Mista.

O índice de equabilidade de Pielou foi ligeiramente diferente entre as áreas analisadas. Para a área com gado, esse valor foi de 0,75 , enquanto que para a área sem gado o valor foi de 0,77 . Com base nesses resultados percebe-se que algumas espécies ocorrem em densidade alta, enquanto outras possuem baixo número de indivíduos. Quanto maior o valor para esse índice, mais igualitária é a distribuição de indivíduos por espécie.

Caldato et al. (1996) avaliaram a regeneração natural na Reserva Genética Florestal de Caçador, SC, para o Tipo Florestal I, no qual ocorre a predominância da espécie Araucaria angustifolia no estrato superior: diferentemente dos resultados obtidos no presente estudo, o valor do índice de equabilidade de Pielou foi de 0,58 , enquanto que no Tipo Florestal II, onde ocorre o predomínio de outras espécies nativas, esse valor foi maior, 0,68. Enquanto que Barddal et al. (2004), no sub-bosque de uma Floresta Ombrófila Mista Aluvial no município de Araucária, PR, obtiveram um valor de equabilidade de 0,68 , bastante diferente do valor obtido para o dossel $(0,47)$ para a floresta aqui analisada.

\section{CONCLUSÃO}

A família Myrtaceae é característica da regeneração natural florestal, apresentando maiores valores no número de indivíduos e de espécies amostradas. Isso faz com que as espécies pertencentes a esse gênero, juntamente com outras espécies características da Floresta Ombrófila Mista, sejam fundamentais em planos de recomposição de áreas que sofreram algum distúrbio natural ou antrópico.

O padrão de distribuição espacial agregado é predominante para as espécies presentes na área de estudo, seguido das espécies com tendência a agregação e das que ocorrem aleatoriamente. Diversas espécies apresentaram o mesmo padrão de dispersão, tanto na área com gado quanto na área sem gado. Esses resultados fornecem subsídios para a tomada de decisão de quais espécies podem ser utilizadas em projetos de recomposição ambiental e quanto à forma de recuperação das áreas degradadas.

A composição, a diversidade e a equabilidade florística encontrada nas áreas submetidas a pastoreio de gado e nas áreas sem a presença do gado foram semelhantes, indicando que a densidade de gado de 22 indivíduos/hectare, em áreas de preservação permanente, não é capaz de influenciar na regeneração natural florestal.

\section{STATUS DA SUBMISSÃO}

Recebido: 20 dez., 2013

Aceito: 10 set., 2014

\section{AUTOR(ES) PARA CORRESPONDÊNCIA}

\section{Luan Demarco Fiorentin}

Departamento de Ciências Florestais, Universidade do Oeste de Santa Catarina UNOESC, CEP 89820-000, Xanxerê, SC, Brasil e-mail: luanfiorentin@hotmail.com

\section{REFERENNCIAS}

Araújo ACB. Efeito do pastoreio de bovinos sobre a estrutura da mata ciliar do Arroio Espinilho em Sant'Ana do Livramento, RS, Brasil [dissertação]. Santa Maria: Universidade Federal de Santa Maria; 2010.

Barddal ML, Roderjan CV, Galvão F, Curcio RG. Fitossociologia do sub-bosque de uma Floresta Ombrófila Mista Aluvial, no município de Araucária, PR. Ciência Florestal 2004; 14(1): 35-45.

Caldato SL, Floss PA, Croce DM, Longhi SJ. Estudo da regeneração natural, banco de sementes e chuva de sementes na reserva genética florestal de Caçador, SC. Ciência Florestal 1996; 6(1): 27-38.

Carvalho JOP. Análise estrutural da regeneração natural em Floresta Tropical Densa na região do Tapajós, no Estado do Pará [dissertação]. Curitiba: Universidade Federal do Paraná; 1982.

Durigan ME. Florística, dinâmica e análise protéica de um Floresta Ombrófila Mista em São João do Triunfo - PR [dissertação]. Curitiba: Universidade Federal do Paraná; 1999. 
Gama JRV, Botelho SA, Bentes-Gama MM, Scolforo JRS. Tamanho de parcela e suficiência amostral para estudo da regeneração natural em Floresta de Várzea na Amazônia. Cerne 2001; 7(2): 1-11.

Gama JRV, Botelho SA, Bentes-Gama MM. Composição florística e estrutura da regeneração natural de Floresta Secundária de Várzea Baixa no Estuário Amazônico. Revista Árvore 2002; 26(5): 559-566. http://dx.doi.org/10.1590/ S0100-67622002000500005.

Kanieski MR. Caracterização florística, diversidade e correlação ambiental na Floresta Nacional de São Francisco de Paula, RS [dissertação]. Santa Maria: Universidade Federal de Santa Maria; 2010.

Klein R. O aspecto dinâmico do pinheiro brasileiro. A Araucaria angustifolia (Pinheiro), como espécie pioneira no atual ciclo climático. Sellowia 1960; 12: 17-51.

Leege TA, Herman DJ, Zamora B. Effects of cattle grazing on Mountain Meadows, in Idaho. Journal of Range Management 1981; 34(4): 324. http://dx.doi.org/10.2307/3897861.

Lingner DV, Oliveira YM, Rosot NC, Dlugosz FL. Caracterização da estrutura e da dinâmica de um remanescente de Floresta com Araucária no Planalto Catarinense. Pesquisa Florestal Brasileira 2007; 55: 55-66.

Mauhs J. Fitossociologia e regeneração natural de um fragmento de Floresta Ombrófila Mista exposto a perturbações antrópicas [dissertação]. São Leopoldo: Universidade do Vale do Rio dos Sinos; 2002.

Narvaes IS, Brena DA, Longhi SJ. Estrutura da regeneração natural em Floresta Ombrófila Mista na Floresta Nacional de São Francisco de Paula, RS. Ciência Florestal 2005; 15(4): 331-342.
Narvaes IS, Brena DA, Longhi SJ. Florística e classificação da regeneração natural em Floresta Ombrófila Mista na Floresta Nacional de São Francisco de Paula, RS. Ciência Florestal 2008; 18(2): 233-245.

Nascimento ART, Longhi SJ, Brena DA. Estrutura e padrões de distribuição espacial de espécies arbóreas em uma amostra de Floresta Ombrófila Mista em Nova Prata, RS. Ciência Florestal 2001; 11(1): 105-119.

Negrelle RAB, Silva FC. Fitossociologia de um trecho de floresta com Araucaria angustifolia (Bert.) O. Ktze. no município de Caçador - SC. Boletim de Pesquisa Florestal 1992; 24/25: 37-54.

Odum EP. Ecologia. Lisboa: Fundação Calouste Gulbenkian; 1988.

Prates AMM, Manzolli JI, Mira MAFB. Geografia física de Santa Catarina. Florianópolis: Editora Lunardelli; 1989.

Sampaio MB, Guarino ESG. Efeitos do pastoreio de bovinos na estrutura populacional de plantas em fragmentos de Floresta Ombrófila Mista. Revista Árvore 2007; 31(6): 10351046. http://dx.doi.org/10.1590/S0100-67622007000600008.

Seger CD, Dlugosz FL, Kurasz G, Martinez DT, Ronconi E, De Melo LAN et al. Levantamento florístico e análise fitossociológica de um remanescente de Floresta Ombrófila Mista localizada no município de Pinhais, Paraná-Brasil. Floresta 2005; 5(2): 291-302.

Téo SJ, Schneider CR, Fiorentin LD, Da Costa RH. Análise fitossociológica de um fragmento de Floresta Ombrófila Mista, em Lebon Régis - SC. In: Anais do $4^{\circ}$ Congresso Florestal Paranaense; 2012; Curitiba. Curitiba: Malinovski Florestal; 2012. 